\title{
Design of Mach-4 and Mach-6 Nozzles for the NASA LaRC 8-Ft High Temperature Tunnel
}

\author{
Richard L. Gaffney, Jr. * \\ NASA Langley Research Center, Hampton, Virginia, 23681-2199, U.S.A
}

\begin{abstract}
The aerodynamic contours for two new nozzles have been designed for the NASA Langley Research Center 8-Foot High Temperature Tunnel. The new Mach-4 and Mach6 contours have 54.5-inch exit-diameters allowing for testing at high dynamic pressures. The Mach-4 nozzle will extend the test capability of the facility and allow turbine-based combined-cycle propulsion systems to be tested at conditions appropriate for the transition from the turbine to the scramjet flowpath. The Mach-6 nozzle will serve a dual purpose; to provide a Mach-6 test capability at high dynamic pressure and to be used in conjunction with an existing mixer section for testing at lower enthalpy conditions. This second use will extend the life of the existing Mach-7 nozzle which has been used for this purpose. The two new nozzles, in conjunction with existing nozzles, will allow for testing at Mach numbers of 3, 4, 5 and 6 at high dynamic pressures, and Mach 4, 5 and 7 at lower dynamic pressures but larger scales.
\end{abstract}

\section{Introduction}

One of the goals of the National Aeronautics and Space Administration is to develop flight systems that provide inexpensive access to space. Systems making use of hypersonic airbreathing propulsion have been proposed as a less expensive, more flexible, and safer alternative to rockets. One of the challenges of this type of propulsion system is the need to operate from take-off to orbit. A proposed solution is to have different types of engines for the different speed ranges; turbine engines for take-off to Mach 3 or 4, scramjet engines for flight to Mach 12 or 15, and rockets for orbit insertion. Propulsion concepts which use both turbine and scramjet engines are called turbine-based combined-cycle (TBCC) propulsion systems. An example of this is given in Figure 1 which shows a TBCC vehicle with two engines that share parts of their flowpath. One of the challenges of this type of system is the transition of the operation from one engine to the other. This dynamic event will require ground tests at a scale large enough for both engines to operate. In anticipation of this, a new Mach-4 capability for the 8-Ft High Temperature Tunnel (8-Ft HTT) has been proposed. While the 8-Ft HTT currently has a Mach-4 nozzle, its very large scale (8-ft exit diameter) limits the dynamic pressures that can be achieved. Reducing the scale of the nozzle to a 54.5 inch exit diameter, while holding the mass flow rate constant, results in 3-fold increase in dynamic pressure over the larger nozzle. A new smaller Mach-4 nozzle will allow for testing of TBCC concepts in the 8-Ft HTT at conditions appropriate for flowpath-transition tests.

A second nozzle has also been proposed and designed for Mach-6 operation. The initial motivation for this nozzle is based on the limited life of the current Mach-7 nozzle. The transpirationally-cooled throat section of this nozzle is currently used for all tests in the 8-Ft HTT. At the Mach-7 test condition, it is used with the full 8-ft exit-diameter Mach-7 contour which extends from the facility combustor to the test cabin. At other (lower) test Mach numbers the throat and transpirationally cooled sections are used in conjunction with a mixer section and a second lower-Mach number nozzle. The structure of the nozzle was designed for a target number of operational cycles, that has now been exceeded. Inspections reveal that the hardware is still in good working condition, however to save the remaining runs in its life for tests at Mach 7, it is necessary to build a new nozzle which can be used with the mixer for lower Mach number testing. The

\footnotetext{
*Aerospace Engineer, Hypersonic Air breathing Propulsion Branch, Senior Member AIAA.
} 


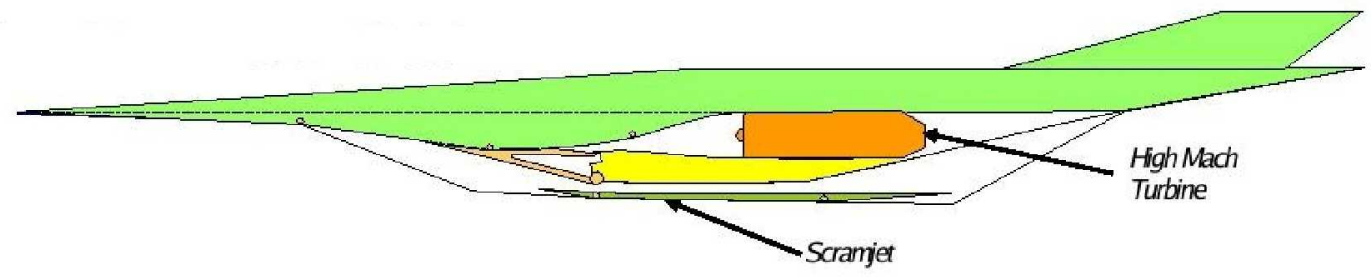

Figure 1. Conceptual arrangement of a TBCC flowpath.

Mach-7 nozzle, while having a very large exit area, is limited in the dynamic pressures that can be achieved. A new 54.5-inch exit-diameter Mach-6 nozzle will provide the facility with another test Mach number at high dynamic pressures and will be built with an adapter piece so that it can be used with the mixer and other nozzles in order to extend the life of the Mach-7 nozzle.

\section{The NASA Langley 8-Ft HTT}

The NASA Langley 8-Foot High Temperature Tunnel ${ }^{1}$ is a combustion-heated hypersonic blowdown-toatmosphere wind tunnel that provides flight-enthalpy simulation for Mach numbers ranging from 3 to 7 . (The Mach-3 capability was recently added ${ }^{2}$ but has not yet been used for tests.) The open-jet test section is a 26 foot diameter sphere and can accommodate large air-breathing hypersonic propulsion systems. At these various test conditions, stable test flow can be provided for periods up to 120 seconds (and up to 5 minutes at the Mach-3 enthalpy condition). The high enthalpy/temperature test flow is achieved via the combustion of air and methane in a high-pressure facility combustor. For air-breathing propulsion tests, oxygen is added to the test medium so that the post-combustion test gas contains twenty-one percent molar oxygen.

The facility currently has three 8-ft exit-diameter nozzles with exit Mach numbers of 4,5 and 7 and two 54.5-inch exit-diameter nozzles with exit Mach numbers of 3 and 5. The 8-ft diameter Mach 4 and 5 nozzles were designed to share the final 220 inches of the Mach-7 contour, which is permanently fixed in place. The two 54.5-inch exit-diameter nozzles are able to achieve higher dynamic pressures than the 8-ft exit-diameter nozzles due to their smaller diameters. The 264 foot tunnel spans two large rooms and extends outside of the building. A bulkhead where the facility nozzle passes through the wall between rooms forms the interface between the upstream nozzle sections and the fixed 220-inch downstream section. For Mach-7 operation, the flow exiting the facility combustor passes through a transpirationally cooled throat section and expands in the Mach-7 nozzle to the test cabin. The Mach-7 nozzle configuration is shown in the upper half of Figure 2. For the Mach 4 and 5 test conditions, a section of the Mach-7 nozzle between the transpirationally cooled throat and the downstream bulkhead is removed and a mixer section and a lower Mach number nozzle are added to the flowpath (lower half of Figure 2). In the mixer, crossflow jets create shockwaves which drive the flow subsonic. These ambient-temperature air jets mix with the hot combustor flow to reduce the temperature to the target test enthalpy. From the mixer, the flow passes through a second throat and expansion section into the test cabin. The large-scale Mach-4 and Mach-5 configurations have different throat and expansion sections up to the bulkhead. Downstream of the bulkhead they share the same contour as the Mach-7 configuration.

The mixer is also used with the 54.5-inch exit-diameter Mach-3 and Mach-5 nozzles which each have their own throats and downstream expansion sections. These nozzles, designated M3HiQ and M5HiQ respectively, are not only smaller in diameter but also in length, measuring 206 inches from the throat to the end of the contour. A 195.6-inch constant area pipe connects the contoured section of the nozzles to the test cabin. All of the nozzle hardware downstream of the bulkhead is mounted inside the downstream section of the fixed 8-ft exit-diameter section. Figure 3 shows a schematic of the M5HiQ nozzle installed in the 8-Ft HTT while Figure 4 is a photograph of the 54.5 inch nozzle exit. 

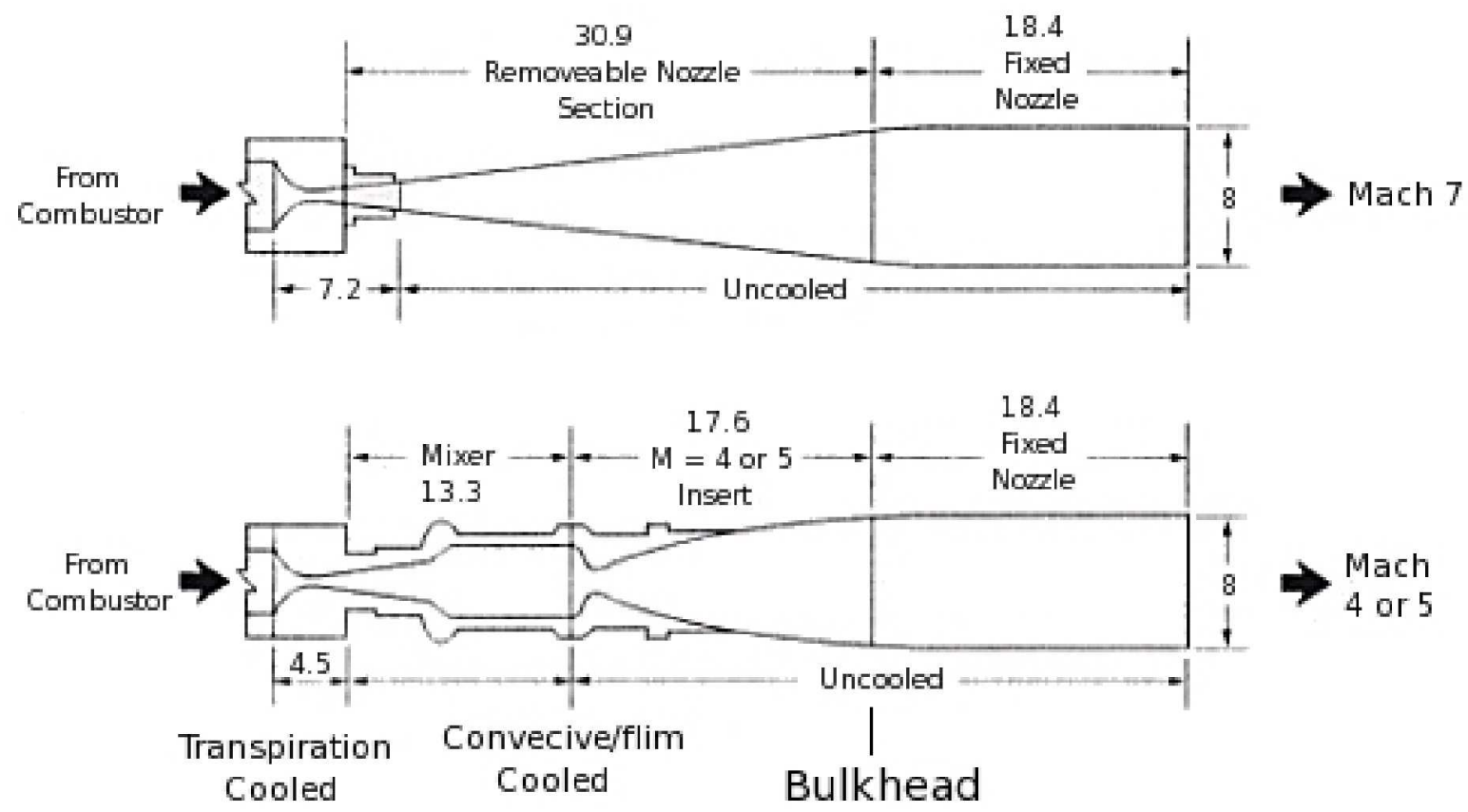

Figure 2. 8-Ft HTT Nozzle Configurations. (Dimensions in Feet)

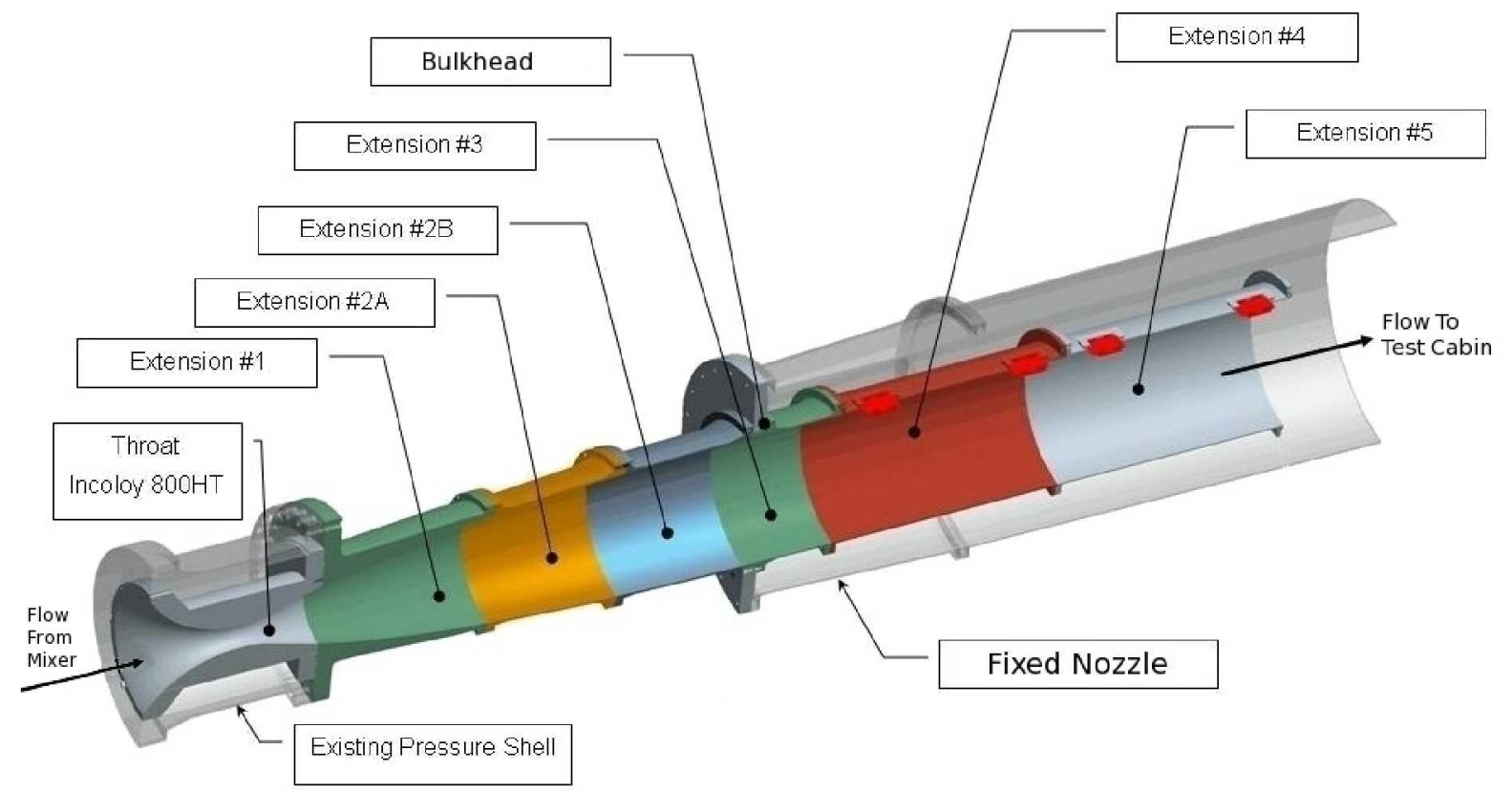

Figure 3. Schematic of the M5HiQ nozzle installed in the facility.

\section{Design Constraint}

The M5HiQ nozzle was the first 54.5 inch diameter nozzle designed for the facility. The contour of this nozzle extends 24.4 inches past the bulkhead between building sections. The contour is connected to the test cabin by a constant diameter pipe. To simplify construction, transportation and installation, the M5HiQ 


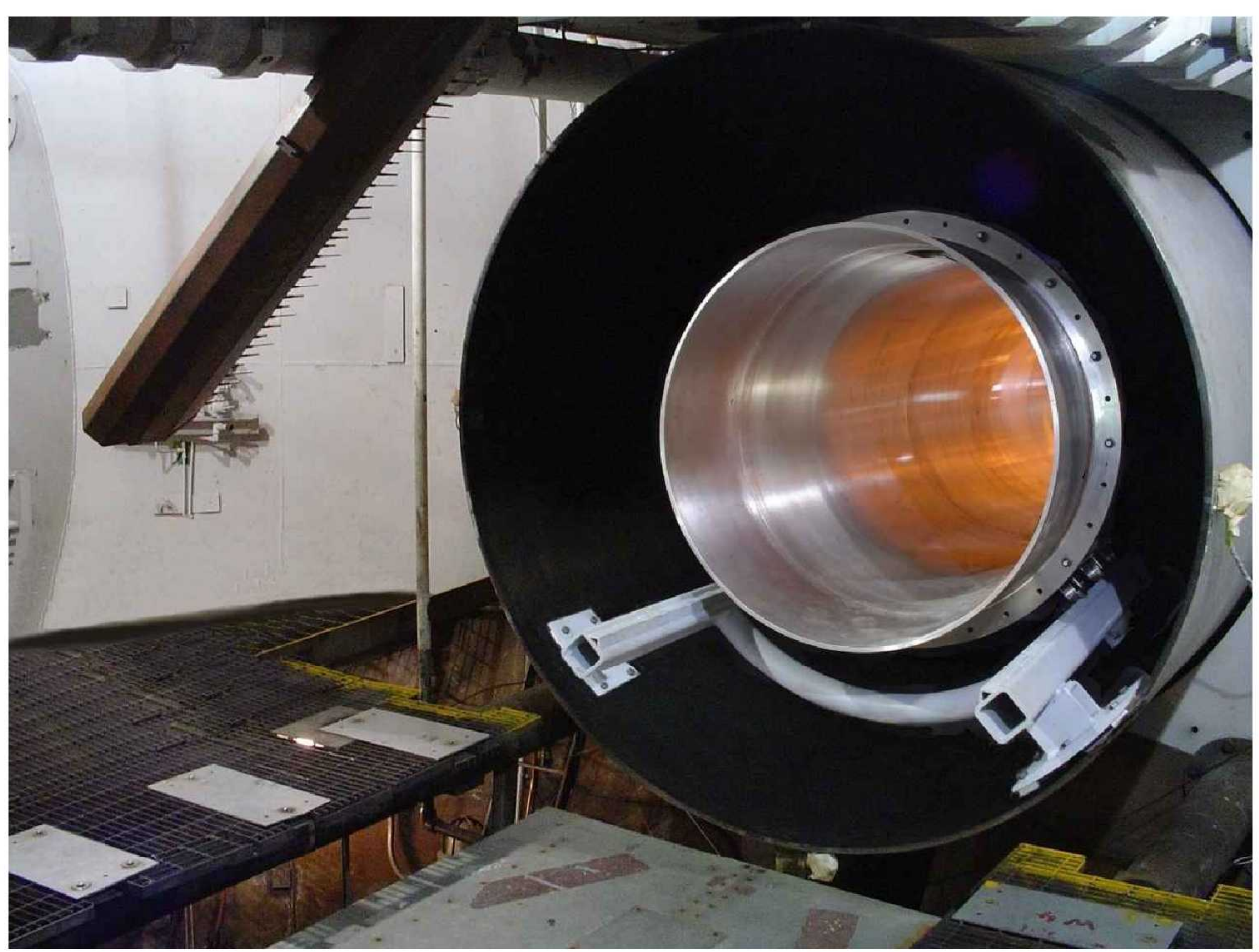

Figure 4. The exit of the 54.5 inch nozzle section installed in the facility.

nozzle was manufactured in sections. Extension \# 3 (Figure 3) of the nozzle begins 5.1 inches upstream of the bulkhead and includes the final 29.5 inches of the contoured section and the first 1.6 inches of the constant area section. The bulkhead was welded to extension 3 and forms a pressure vessel with the permanently fixed 220-inch large-diameter section, test cabin and diffuser. In order to reduce construction costs for both new nozzles, the decision was made to re-use extension \# 3 and the downstream sections. Since this section includes the final portion of the M5HiQ nozzle, the new contours must blend smoothly into this section, creating a minimum of flow distortion at the entrance to the test cabin.

\section{Design Methodology}

The design procedure consisted of three steps: the inviscid contour generation, a viscous evaluation/correction and the blending of the new contour with the existing downstream section. Each of these steps is discussed below.

\section{A. Inviscid Design}

Contours for the supersonic portion of the new nozzles were generated using the IMOCND ${ }^{3,4}$ (Irrotational Method of Characteristics for Nozzle Design) code. This code requires the user to specify the ratio of specific heats, $\gamma$, of the test gas, the throat and initial expansion surface of the nozzle and a target exit Mach number. From these, the code generates a turning surface that produces uniform flow at the nozzle exit. The user can specify the throat and expansion surface in several different ways: a circular arc, a Gaussian curve or a user-specified polynomial curve. For the circular arc and Gaussian curve options, the user specifies a radius of curvature at the throat and the code determines, in an iterative fashion, the amount of expansion that will produce the target exit Mach number. The length of the nozzle is a function of the target exit Mach number, the throat radius of curvature and one physical dimension (i.e. exit radius). A larger throat radius of curvature produces a longer nozzle and a more gentle expansion of the flow. When viscous effects are considered, the longer nozzle usually produces a more uniform exit flow but at the expense of a thicker boundary layer. As will be discussed in the section on blending, the radius of curvature was set so that the final contours had the proper length and radius to match the start of the extension \#3 contour. 
As mentioned earlier, the IMOCND code requires the user to specify a value for the ratio of specific heats. In the facility, $\gamma$ varies significantly from the hot plenum to the much cooler nozzle exit. Since the code only uses a single value of $\gamma$, the value which gives an optimum contour was determined for each nozzle in an iterative fashion. The initial value was taken as the average between the value at stagnation conditions and the value at the target Mach number. Three contours were generated using the average value, and values slightly higher and lower. Viscous, variable- $\gamma$ CFD solutions (see next section) were computed and the level of non-uniformity in static pressure at the exit determined for each solution. The pressure variation (maximum value - minimum value) vs. $\gamma$ was curve fit and the value of $\gamma$ producing the minimum non-uniformity was selected as the value to use in the design process.

There is no analytic method available for the design of the subsonic portion of the nozzle, although there are some general rules of thumb. These include keeping the contour and its 1st derivative continuous at the throat and properly specifying the radius of curvature in the throat region. The radius of curvature on the subsonic side of the contour affects the shape of the sonic line (which is actually curved) at the throat; a larger radius of curvature produces a flatter sonic line. Currently the IMOCND code starts the MOC solution with a straight line of constant Mach number (slightly greater than 1.0), so a larger radius of curvature on the subsonic side of the contour gives a better approximation to this starting profile. For simplicity, often times the curve used for the supersonic expansion is extended (or reflected) to the subsonic side. Since the subsonic contour must match some upstream geometry, it is typical to use a second curve, usually a polynomial, to smoothly transition from the subsonic side of the throat contour to the given upstream geometry. A fourth-order polynomial allows the user to specify the coordinates and their slopes at both ends and the 2nd derivative at the throat end, resulting in a smooth transition between curve segments.

\section{B. Viscous Evaluation/Correction}

The method of characteristics is an inviscid design method. In order to include viscous effects in the design, the flow quality resulting from the subsonic and IMOCND generated contours is evaluated with a NavierStokes CFD solver. Generally the CFD-computed exit properties will not match the target values due to the presence of the boundary layer. In this case, the target exit Mach number input into the IMOCND code is adjusted and a new contour generated. The new contour is evaluated with the CFD code and exit conditions checked. Additional iterations are performed to achieve the target exit conditions. Generally this only requires a few iterations.

For the two new nozzles, viscous CFD calculations were performed with the VULCAN CFD code. ${ }^{5}$ This code solves the two-dimensional, axisymmetric or three-dimensional Euler or Favre-averaged Navier-Stokes equations using a finite-volume discretization on a structured grid. Continuity equations for chemical species, including source terms for finite-rate chemical reaction, can be included as part of the calculation. There are a number of options for modeling thermodynamics, convective fluxes, and turbulence. For the nozzle design calculations, the axisymmetric thin-layer Navier-Stokes equations were solved. The gas was modeled as a mixture of thermally-perfect, calorically-imperfect gases. ${ }^{6}$ Roe's upwind flux difference split scheme ${ }^{7}$ with a third order MUSCL stencil and a limiter by Van Leer ${ }^{8}$ were used to model the convective fluxes. Turbulence was modeled using the k-omega model of Wilcox. ${ }^{9}$

The grids used in the design calculations had 1,281 points in the streamwise direction and 129 points in the radial direction. The geometry extended from the converging section upstream of the throat to the entrance of the test cabin. The grid was clustered near the wall in the radial direction resulting in a $y+$ spacing of less than 0.9 along the length of the calculations.

The inflow boundary of of the computational domain was set to a subsonic inflow boundary condition. This boundary condition requires the user to input a total pressure, total temperature and a gas composition. The outflow boundary was set to a supersonic outflow boundary condition which extrapolates all the flow properties from the interior to the boundary. For the final design, two calculations were made for each nozzle with different thermal wall boundary conditions. This included both an adiabatic and an isothermal wall boundary condition. For all cases, the $\mathrm{L}_{2}$ norm of the residual was iteratively reduced by approximately 8 orders of magnitude. 


\section{Blending The Contours}

As discussed previously, the new nozzle contours must have the same radius (27.1365 inches) as that of the M5HiQ nozzle at the start of extension \#3. Ideally, they should also match the M5HiQ contour slope at this section while achieving the target Mach number at the entrance to the test cabin with a minimum of flow distortion. Matching the radius at the start of extension \#3 was accomplished by choosing a Gaussian-curve expansion section and adjusting the throat radius of curvature input into the IMOCND code to vary the length of the contour. The exit radius was set to 27.24 inches (the radius of the constant area sections) and the input Mach number set to the target Mach number. The length was varied, via the throat radius of curvature, until the radius of the new contour matched the radius at the start of extension \#3. This was an iterative procedure requiring several runs of the IMOCND code. This resulted in contours (both the Mach 4 and 6) that overlapped the M5HiQ contour while matching the radius at the start of extension \#3. The contour downstream of the match point was discarded and replaced with the M5HiQ contour and the constant area section. The new nozzle flowfield, including the constant area sections, was computed with the VULCAN CFD code. Several iterations were made, adjusting the Mach number input into the IMOCND code, to achieve the target exit Mach number. Note that this procedure required an inner iteration to match the radius and an outer iteration to match the target exit Mach number.

There was a little bit of flexibility in specifying the length of the supersonic portion of the contour because the length of the subsonic contour was not fixed and could be adjusted as needed. The subsonic side of the throat contour was specified as a Gaussian curve that was connected to the upstream plenum via a fourth-order polynomial. At the subsonic contour end, the polynomial matched the radius, and the 1st and 2nd derivatives of the Gaussian curve. At the plenum end, the polynomial matched the radius of either the mixer or the facility combustor at a set angle.

The above procedure produced contours with the correct exit Mach number, and length and radius to match the pre-existing hardware. However, it resulted in contours with a slope discontinuity at the start of extension \# 3. Fortunately for both nozzles the discontinuity in slope is small and is positioned near the end of the contour where the thick boundary layer helps to reduce the effects of the discontinuity on the core flow. To further weaken waves created at the interface of the two contours, the slope discontinuities were removed by replacing several inches of the IMOCND generated contour with a third-order polynomial, matching the radius and slope at each end. Note that this weakens waves by spreading them out along the polynomial segment, but does not remove them.

\section{Mach-4 Nozzle}

The Mach-4 nozzle was designed using the above outlined procedure. The total conditions in the mixer were determined from target test conditions and are given in Table 1. The gas composition, given in Table 2, was determined from a chemical equilibrium calculation using expected facility mass flow rates of air, oxygen and methane into the facility combustor, nozzle and mixer. The optimal value of $\gamma$ was found to be 1.36. The radius of curvature at the throat was set to 15 throat radii, resulting in a throat diameter of 14.94 inches and a contour that extends 445.4 inches from the mixer exit to the start of extension \#3. At the subsonic end, the contour meets the 48 inch diameter mixer exit at a slope of 60 degrees. The viscous CFD evaluation was done using an isothermal wall temperature of 500 Kelvin. The MOC generated contour had a 0.02 degree slope discontinuity at the start of extension \# 3. At this axial location the boundary layer is 3.2 inches thick which helps to reduce the effects of the discontinuity on the core flow. To further reduce the effects, the discontinuity was removed by replacing the final 2 inches of the MOC generated contour with a contour from a third-order polynomial curve fit.

The final design was evaluated using viscous CFD and found to expand the flow smoothly from the mixer to the test cabin. Contours of Mach number in the nozzle are shown in Figure 5. Note that the Mach number at the exit of the contoured section (start of the constant area section) is slightly greater than the target exit Mach number because the boundary layer growth in the constant area section reduces the Mach number slightly. The Mach number and static pressure profiles at the entrance to the test cabin are shown in Figure 6. This nozzle achieves the Mach-4 target exit Mach number with a static pressure non-uniformity 
of only 1.22 percent (maximum value to minimum value). The boundary layer at the exit is about 5.6 inches thick, leaving a uniform core about 43.3 inches in diameter.

\begin{tabular}{|c|c|c|}
\hline Mach Number & $\begin{array}{c}\text { Total Temperature } \\
\text { Rankine }\end{array}$ & $\begin{array}{c}\text { Total Pressure } \\
\text { PSI }\end{array}$ \\
\hline 4.0 & 1540 & 100 \\
6.0 & 2850 & 1500 \\
\hline
\end{tabular}

Table 1. Target Design Properties

\begin{tabular}{|c|c|c|}
\hline Species & Mach 4 & Mach 6 \\
\hline $\mathrm{N}_{2}$ & 0.71609 & 0.5750 \\
$\mathrm{O}_{2}$ & 0.20739 & 0.2153 \\
$\mathrm{CO}_{2}$ & 0.02268 & 0.0676 \\
$\mathrm{H}_{2} \mathrm{O}$ & 0.04533 & 0.1352 \\
$\mathrm{Ar}$ & 0.00852 & 0.0069 \\
\hline
\end{tabular}

Table 2. Test Gas Composition, mole fractions

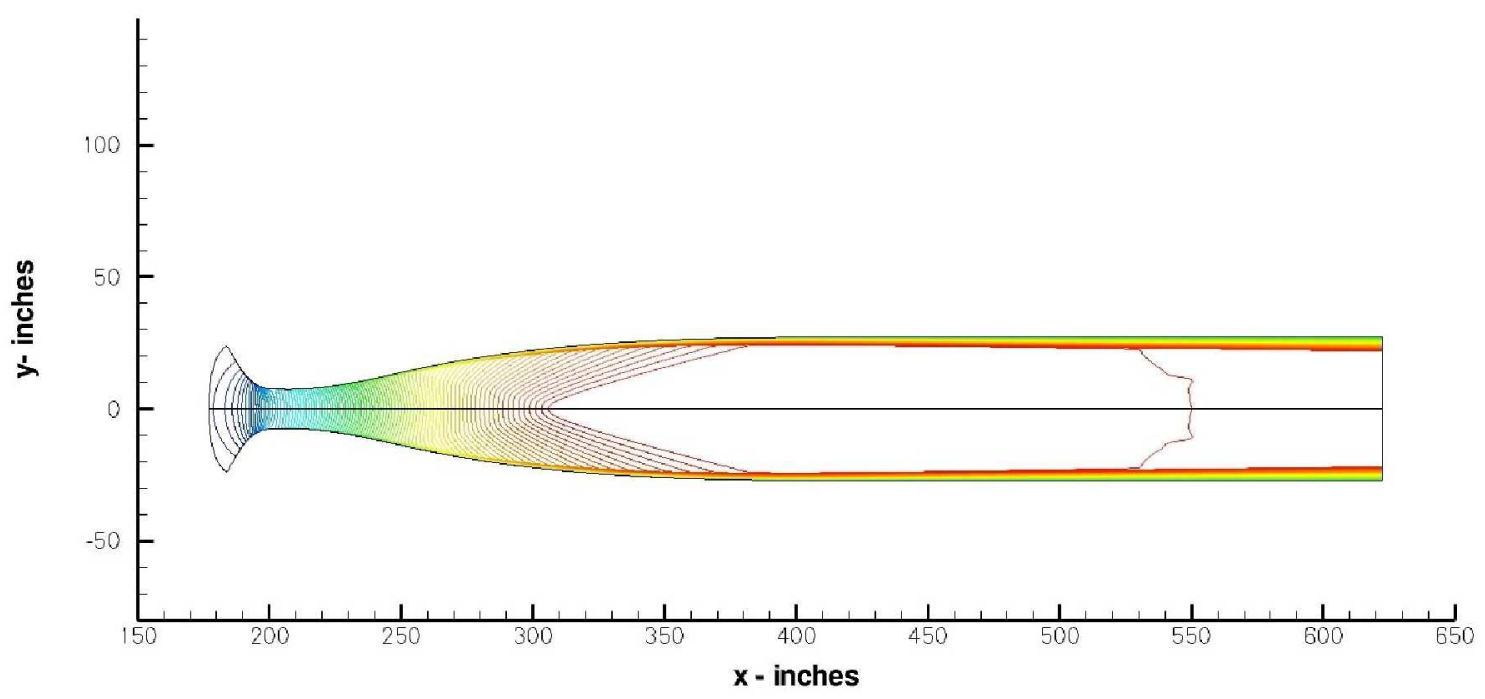

Figure 5. Mach number contours in the M4HiQ nozzle.

\section{Mach-6 Nozzle}

The Mach-6 nozzle was also designed using the above outlined procedure. The total conditions at the exit of the facility combustor were determined from target test conditions and are given in Table 1 . The gas composition is given in Table 2. At this higher enthalpy condition, the optimal value of $\gamma$ was found to be 1.315. Since the facility combustor was 648.3 inches from the start of extension \# 3, the Mach-6 nozzle had to be much longer than the Mach-4 nozzle. This was accomplished by setting the throat radius of curvature to 321 throat radii. The result is a contour which expands the flow very slowly from the 5.37 inch diameter throat to the end of the contoured section. At the subsonic end, the contour meets the 36 inch diameter combustor exit with a slope of 0 degrees. The viscous CFD evaluation was done using an isothermal wall 


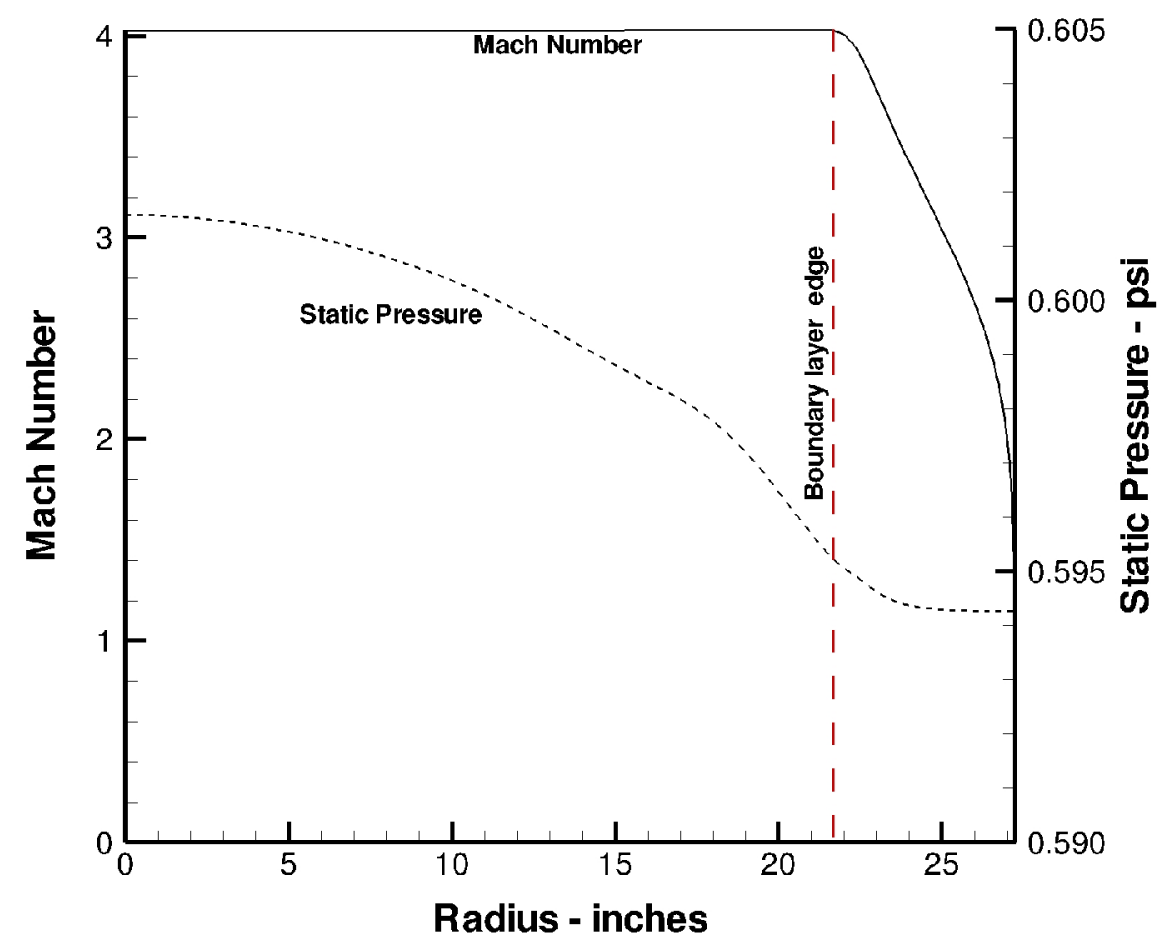

Figure 6. Exit profiles Mach number and pressure for the M4HiQ nozzle.

temperature of 800 Kelvin. The MOC generated contour had a 0.17 degree slope discontinuity at the start of extension \# 3. At this axial location the boundary layer is 7.7 inches thick which helps to reduce the effects of the discontinuity on the core flow. To further reduce the effects, the discontinuity was removed by replacing the final 4 inches of the MOC generated contour with a contour from a third-order polynomial curve fit. Like the curve fit for the Mach-4 nozzle, this does not remove the generation of a wave, only spreads it out over several inches, reducing its effects.

The final design was evaluated using viscous CFD and found to expand the flow smoothly from the facility combustor to the test cabin. Contours of Mach number in the nozzle are shown in Figure 7. Again note that the Mach number at the exit of the contoured section (start of the constant area section) is slightly greater than the target exit Mach number because the boundary layer growth in the constant area section reduces the Mach number slightly. The Mach number and static pressure profiles at the entrance to the test cabin are shown in Figure 8. This nozzle achieves the target exit Mach number with a static pressure non-uniformity of only 1.18 percent (maximum value to minimum value). The boundary layer at the exit is about 9.25 inches thick, leaving a uniform core about 36 inches in diameter.

\section{Outstanding Issues}

There are two issues which remain outstanding in the current designs and which may affect their performance. They are condensation in the nozzle and high turbulence levels in the plenum upstream of the throat.

\section{A. Condensation}

The calibration of the M5HiQ nozzle exit flow using total temperature, Pitot and static pressure probes resulted in a computed exit Mach number of about 4.6. This was surprising as the nozzle was designed for 


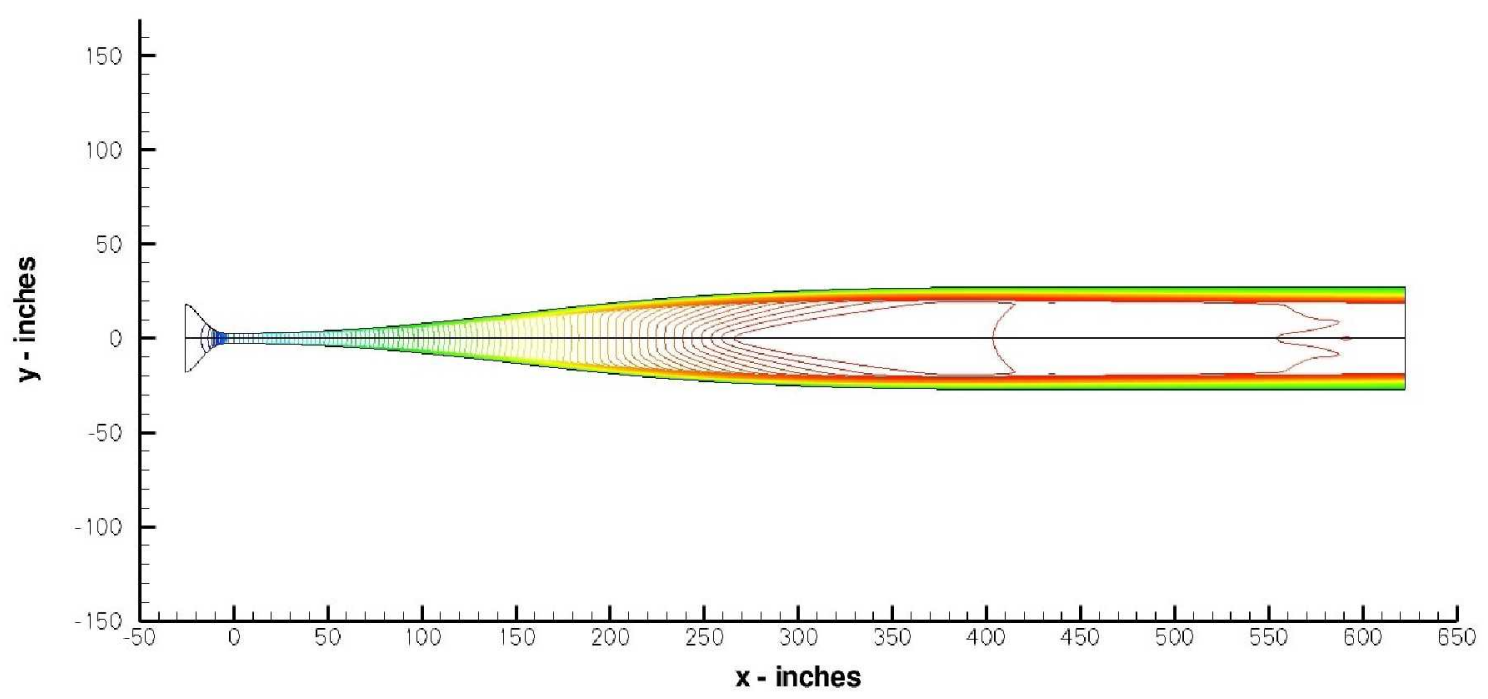

Figure 7. Mach number contours in the M6HiQ nozzle.

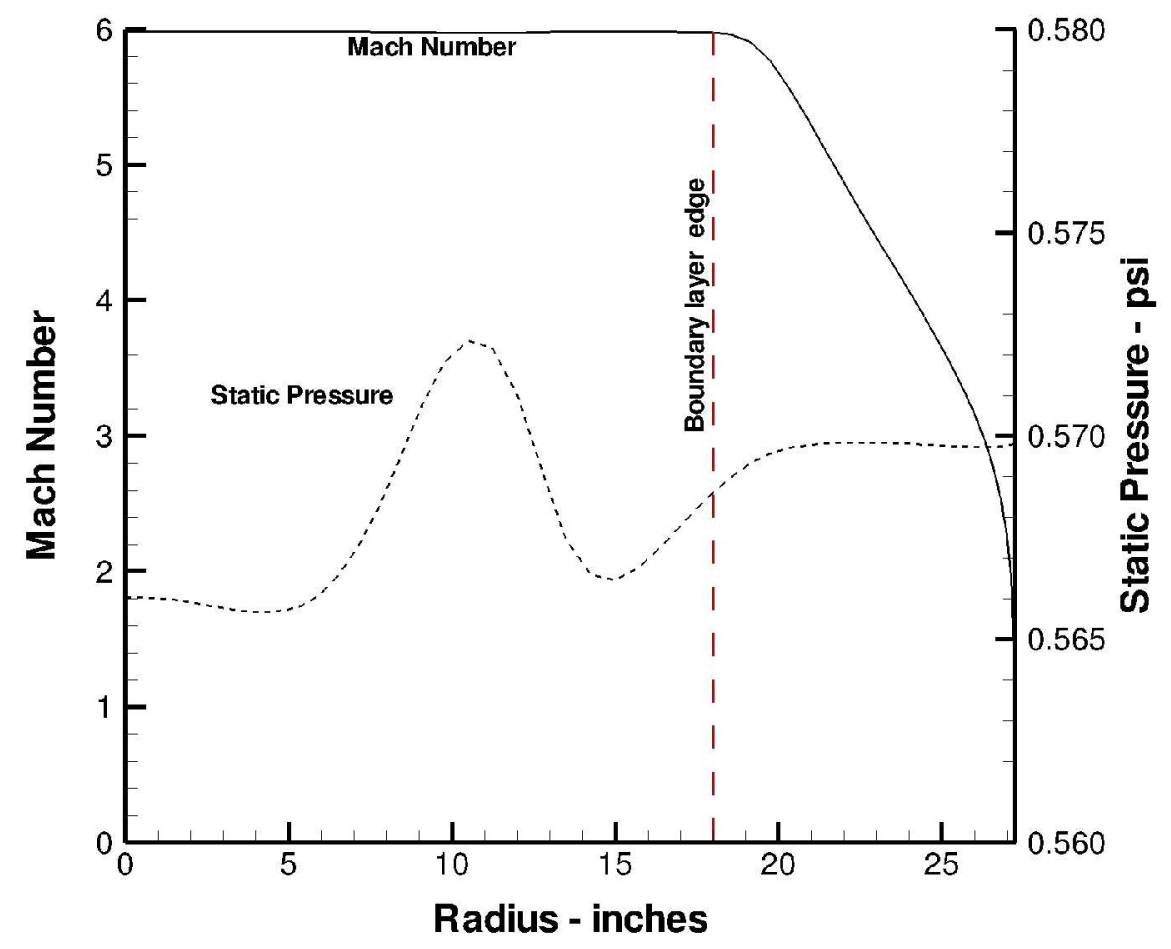

Figure 8. Exit profiles Mach number and pressure for the M6HiQ nozzle.

Mach-5 exit-flow. The cause of the low computed Mach number was thought to be condensation of water vapor generated in the facility combustor. Condensation releases heat into the flow, raising the temperature and dropping the Mach number. A study by Cox-Stouffer et. al ${ }^{10,11}$ indicated that if the condensed flow 
passes through a sufficiently strong shockwave, the flow re-vaporizes, resulting in flow properties close to that of a flow that never condensed. The normal shockwaves in front of the total temperature and Pitot probes are sufficiently strong and revaporize the condensation. However, the shockwave generated by the tip of the static pressure probe is not not sufficiently strong to revaporize the flow, and the condensation remains. This produces an inconsistency when processing the probe data, as two of the probes are measuring gaseous flow while the third is measuring flow with condensation. This leaves the actual Mach number of the nozzle exit flow somewhat in question. The matter is further complicated when the shockwave generated by the test article is sufficiently strong to revaporize condensation. The revaporization will remove heat from the flow, dropping the speed of sound and increasing the Mach number, returning the flow to a Mach number near to what would have been had the flow never condensed.

\section{B. Turbulence}

The Mach-3 nozzle was designed using the same procedure as outlined in this paper for the Mach-4 and Mach6 nozzles. Since the throat of the Mach-3 nozzle is quite a bit larger than that of the M5HiQ nozzle, there was some concern that large-scale flow structures, generated in the mixer, could persist and pass through the throat, affecting nozzle performance. To resolve this issue, 3-D CFD calculations of the flowfield from the exit of the facility combustor to the test cabin were performed. Of particular concern was the mixing of the hot and ambient temperature streams and the species concentrations. The calculations indicated that the mixer was performing as desired, resulting in fairly uniform flow at the entrance to the test cabin. Based on these results, the nozzle was built and installed in the tunnel for calibration. However the computed Mach number, using measurements from the facility total temperature, Pitot and static pressure probes, was only 2.8. Again, this was below the design Mach number. Like the M5HiQ calibration, the calibration was done with water vapor in the flowfield. However, the Mach-3 flow has considerably more ambient-temperature air added in the mixer, lowering the percentage of water vapor in the flow. Since the amount of water vapor is much smaller than for the M5HiQ nozzle, one would expect the effects of condensation to be reduced. In an attempt to identify another possible source of the reduced Mach number, a recalculation of the full 3-D geometry, using the actual mixer flow rates and injection sites was done. This calculation indicated that the exit Mach number was only 2.9. This suggests that part of the Mach number decrease is due to turbulence generated in the mixer which affects the growth of nozzle boundary layer. This effect is ignored in the current design procedure since the flow in the plenum is assumed to be uniform with low levels of turbulence.

\section{Proposed Test}

After calibration, the Mach-3 nozzle was removed and replace with the Mach-7 nozzle for a scheduled test program. It has been proposed to re-install the Mach-3 nozzle at the end of the current test series and conduct an additional nozzle calibration test. This test would be to run the facility without combustion in the facility combustor. For higher Mach numbers, the combustor must be run to prevent the condensation of the various species forming air $\left(\mathrm{N}_{2}, \mathrm{O}_{2}, \mathrm{CO}_{2}\right)$. However, the expansion of room temperature air to Mach 3 results in an exit temperature high enough to prevent condensation of the major species (but not $\mathrm{H}_{2} \mathrm{O}$ ). Since the high pressure air provided to the facility is dried, water vapor and its condensation should be minimal. This test would provide information on how water condensation affects the exit Mach number. It has also been proposed to add temporary boundary layer rakes at the nozzle exit to better measure the actual boundary layer thickness for comparison with the CFD. Base on the results from these tests, the contours for the Mach-4 and Mach-6 nozzles can be accepted as they are, or undergo an additional design iteration to provide the desired exit Mach numbers.

\section{Summary}

The aerodynamic contours for two new nozzles have been designed for the 8-Ft High Temperature Tunnel at NASA Langley Research Center. The Mach-4 high dynamic pressure nozzle will allow turbine-based combined-cycle dual-flowpath configurations to be tested in the facility in the speed range of transition from one flowpath to the other. The Mach-6 high dynamic pressure nozzle will increase the high dynamic pressure test capability of the facility from a flight Mach number of 5 to 6 . It will also be used to extend the life of the existing Mach-7 nozzle by being used with a mixer section for lower enthalpy tests. To reduce construction 
costs, both new nozzles were designed to re-use the last part of the Mach-5 nozzle contour. Both nozzles have a non-uniformity in exit static pressure of less than 1.25 percent (maximum value to minimum value). The issues of flow condensation and turbulence levels in the mixer, and their effects on nozzle performance, are under investigation and may result in an additional design iteration if it is deemed appropriate.

\section{References}

${ }^{1}$ Guy, R. W., Rogers, R. C., Puster, R. L., Rock, K. E. and Diskin, G. L., "The NASA Langley Scramjet Test Complex," AIAA paper 96-3243, July, 1996.

${ }^{2}$ Gaffney, R. L., Jr. and Norris, A. T., "Design of a Mach-3 Nozzle for TBCC Testing in the NASA LaRC 8-Ft High Temperature Tunnel," AIAA paper AIAA-2008-3703, June, 2008.

${ }^{3}$ Gaffney, R. L. Jr," "Design Of A Pulse-Facility Nozzle Using The Rotational Method Of Characteristics," Journal of Spacecraft and Rockets, Vol 43, Number 6, 2006.

${ }^{4}$ Gaffney, R. L., Jr., Stewart, B. K., Harvin, S. F., "The Design Of A High-Q, Mach-5 Nozzle For The NASA Langley 8-Foot HTT," AIAA paper No. 2006-2954, 2006.

${ }^{5}$ VULCAN, "http://vulcan-cfd.larc.nasa.gov", July 2009.

${ }^{6}$ McBride, B. J., Gordon, S. and Reno, M. A., "Thermodynamic Data for Fifty Elements," NASA TP-3287, January, 1993.

${ }^{7}$ Roe, P. L., "The Use of the Riemann Problem in Finite Difference Schemes," Proceedings of the Seventh International Conference on Numerical Methods in Fluid Dynamics, Stanford, California, June 23-27, 1980, Lecture Notes In Physics, Vol. 141, pp. 354-359. Springer-Verlag, Berlin, 1981.

${ }^{8}$ Hirsch, C., Numerical Computation of Internal and External Flows, Volume 2: Computational Methods for Inviscid and Viscous Flows, Chichester: John Whiley \& Sons, 1992.

${ }^{9}$ Wilcox, D. C., Turbulence Modeling for $C F D, 2^{\text {nd }}$ ed., San Diego, Ca.: DCW Industries, 2006.

${ }^{10}$ Cox-Stouffer, S. K., Cabell, K. F., and Edwards, J. R., "A Numerical Evaluation Of The Effects Of Water Condensation On Wind Tunnel And Forebody Performance For GDE-2," JANNAF Joint CS/APS/PSHS Conference paper, December, 2006.

${ }^{11}$ Cox-Stouffer, S. K., Cabell, K. F., and Edwards, J. R., "The Effects Of Water Condensation In The NASA Langley 8-Ft. High Temperature Tunnel At X-51A Test Conditions," JANNAF Joint CS/APS/EPTS/PSHS Conference paper, May, 2008. 